\title{
Further Analysis on the Mystery of the Surveyor III Dust Deposits
}

\author{
Philip Metzger ${ }^{1}$, Paul Hintze ${ }^{1}$, Steven Trigwell ${ }^{2}$, John Lane ${ }^{3}$ \\ ${ }^{1}$ Granular Mechanic and Regolith Operations Lab, NASA, Kennedy Space Center, FL 32899 \\ ${ }^{2}$ Applied Technology, Siera Lobo-ESC, Kennedy Space Center, FL 32899 \\ ${ }^{3}$ Granular Mechanics and Regolith Operations, Easi-ESC, Kennedy Space Center, FL 32899
}

\begin{abstract}
The Apollo 12 lunar module (LM) landing near the Surveyor III spacecraft at the end of 1969 has remained the primary experimental verification of the predicted physics of plume ejecta effects from a rocket engine interacting with the surface of the moon. This was made possible by the return of the Surveyor III camera housing by the Apollo 12 astronauts, allowing detailed analysis of the composition of dust deposited by the Apollo 12 LM plume. It was soon realized after the initial analysis of the camera housing that the LM plume tended to remove more dust than it had deposited. In the present study, coupons from the camera housing were reexamined by a KSC research team using SEM/EDS and XPS analysis. In addition, plume effects recorded in landing videos from each Apollo mission have been studied for possible clues. Several likely scenarios are proposed to explain the Surveyor III dust observations. These include electrostatic attraction of the dust to the surface of the Surveyor as a result of electrostatic charging of the jet gas exiting the engine nozzle during descent; dust blown by the Apollo 12 LM fly-by while on its descent trajectory; dust ejected from the lunar surface due to gas forced into the soil by the Surveyor III rocket nozzle, based on Darcy's law; and mechanical movement of dust during the Surveyor landing. Even though an absolute answer is not possible based on available data and theory, various computational models are employed to estimate the feasibility of each of these proposed mechanisms. Scenarios are then discussed which combine multiple mechanisms to produce results consistent with observations.
\end{abstract}

\section{BACKGROUND}

In 1967, an unmanned robotic landing device known as Surveyor III, lifted off from thefor Earth on April 17 and landed on the moon on April 20. The location of the Surveyor III landing was at the Mare Cognitum portion of the Oceanus Procellarum ( $3^{\circ} 01^{\prime} 41.43 S^{\prime \prime} 23^{\circ} 27^{\prime} 29.55^{\prime \prime} \mathrm{W}$ ). Surveyor III transmitted 6,315 photographic images back to the Earth.

The landing of the Surveyor III was far from smooth. According to Wikipedia:

As Surveyor III was landing (in a crater, as it turned out), highly reflective rocks confused the spacecraft's lunar descent radar. The engines failed to cut off at 14 feet (4.3 meters) in altitude as called for in the mission plans, and this delay caused the lander to bounce on the lunar surface twice. Its first bounce reached the altitude of about 35 feet (10 meters). The second bounce reached a height of about 11 feet (three meters). On the third impact with the surface - from the initial altitude of three meters, and velocity of zero, which was below the planned altitude of 14 feet (4.3 meters), and very slowly descending - Surveyor III settled down to a soft landing as intended.

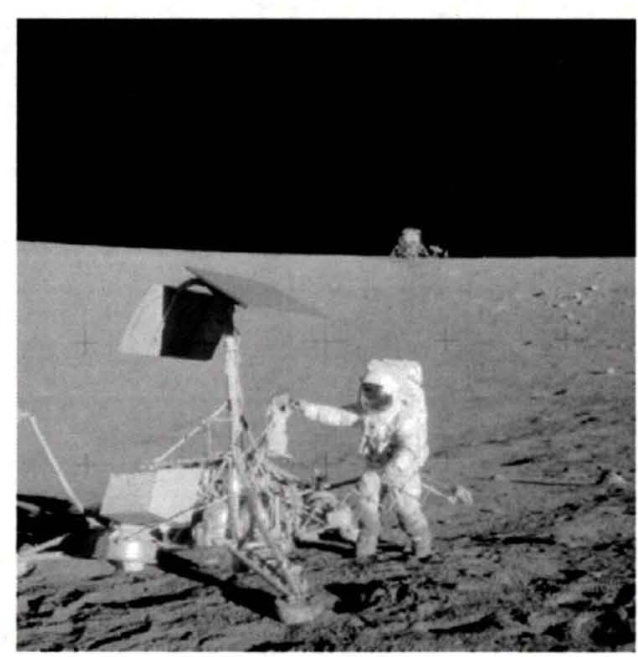

Figure 1: Astronaut Bean examining Surveyor III. Note that the Apollo 12 LM is in the background. 
For over 2 years, Surveyor III simply resided on the surface being exposed to the ravages of space. However, on November 14, 1969, Apollo 12 launched from the Earth (despite being struck twice by lightning during take-off) and landed on the moon on November 19, 1969 at Oceanus Procellarum/Mare Cognitium (Ocean of Storms/Known Sea) at coordinates $3^{\circ} 00^{\prime} 45^{\prime \prime} \mathrm{S}$ $23^{\circ} 25^{\prime} 18^{\prime \prime} \mathrm{W}$ or $3.012389^{\circ} \mathrm{S} 23.421569^{\circ} \mathrm{W}$. The Lunar Module (LM) of the Apollo 12 named Intrepid purposely landed $155 \mathrm{~m}$ to the west from Surveyor III. Apollo 12 astronauts Charles "Pete" Conrad (Commander) and Alan L. Bean (LM Pilot) were able to examine Surveyor III (as shown in Figure 2) and bring parts back to the Earth. It is interesting to note that the seismometers the astronauts had left on the lunar surface registered the vibrations from the LM lift-off for more than an hour.

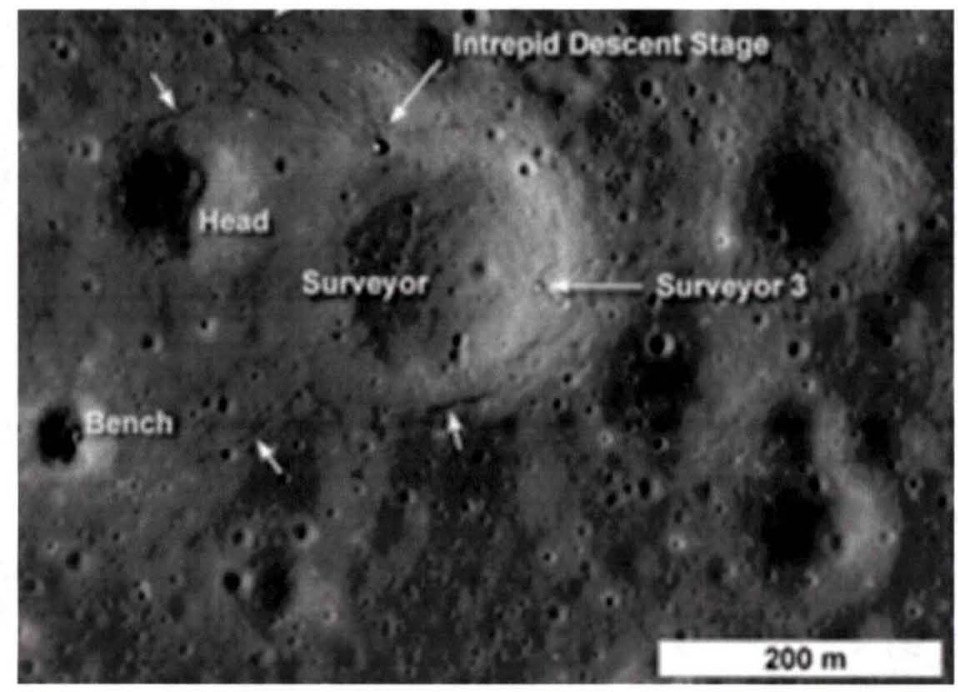

Figure 2: Landing sites of Intrepid and Surveyor III.

The relative landing sites of the Apollo 12 LM and Surveyor III are shown in Figure 2. The astronauts visited the Surveyor III on their second excursion. Lunar samples were taken throughout the excursions totaling a combined weight of $34 \mathrm{~kg}$ of rocks, soil, and core samples (taken down to $40 \mathrm{~cm}$ below the surface regolith). A chemical analysis of most of the samples can be found on the Lunar and Planetary Institute website (http://www.lpi.usra.edu/lunar/missi ons/apollo/apollo_12/samples).

Samples taken near the LM and others taken near to Surveyor III have been tabulated in Appendix A. The goal is to observe if the elemental analysis from XPS and SEM/EDX done in the present study correlates with soil/rocks either near the LM site or near the Surveyor III site.

\section{LUNAR SURVEYOR III SAMPLES}

The Surveyor III parts brought back to Earth by Apollo 12 are currently stored at the Johnson Space Center (JSC) Lunar Sample Curation (http://www-curator.jsc.nasa.gov/lunar /index.cfm), and information on the chemical analyses is found at the Lunar and Planetary Institute (http://www.lpi.usra.edu). Several of the parts were requested and sent to KSC for analysis in the present study (see and Figures 3 and 4). Those parts are summarized in Table 1. 


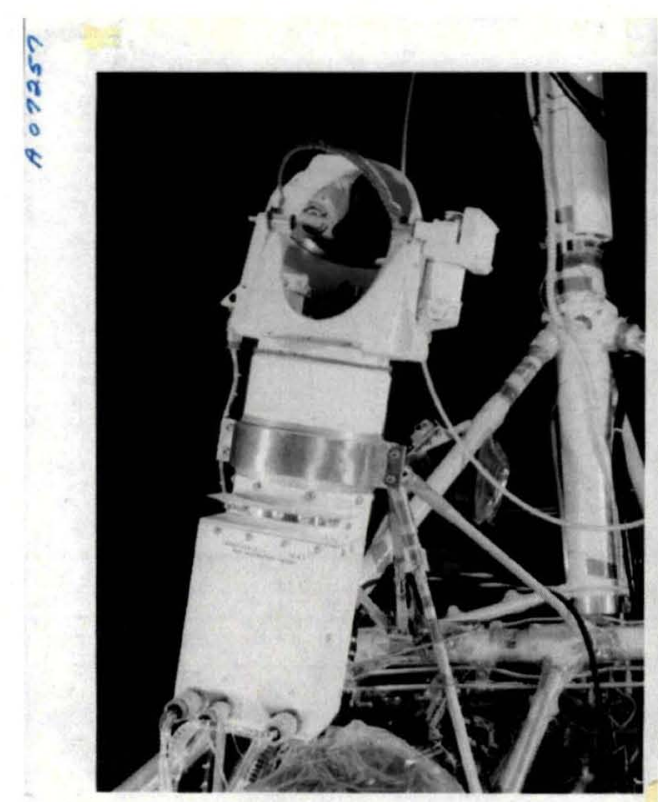

Figure 4: Surveyor III camera on the moon.

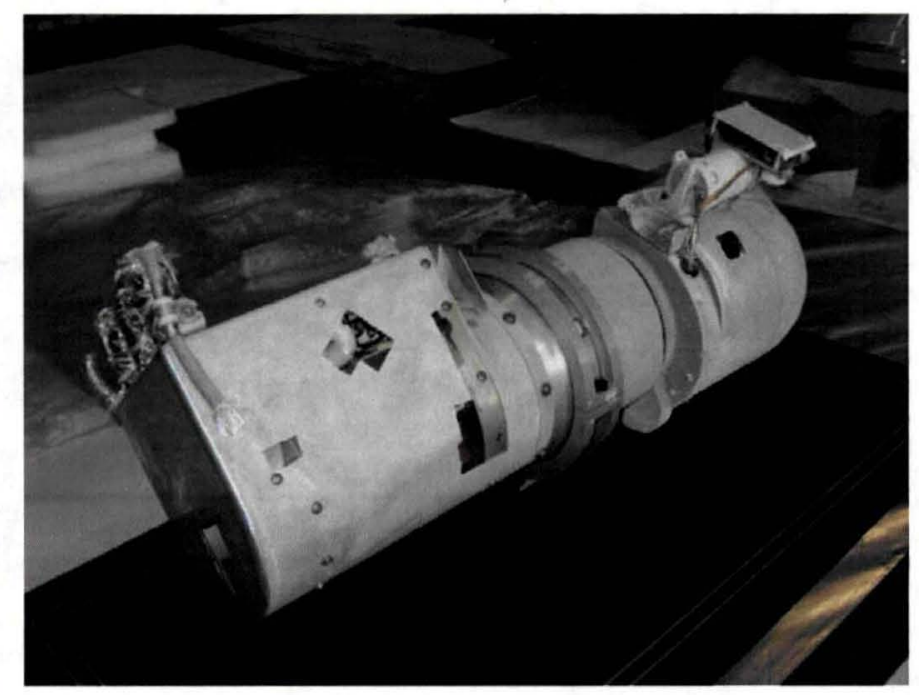

Figure 3: The camera module showing the bottom cutout.

Table 1. Surveyor III Parts Under Investigation.

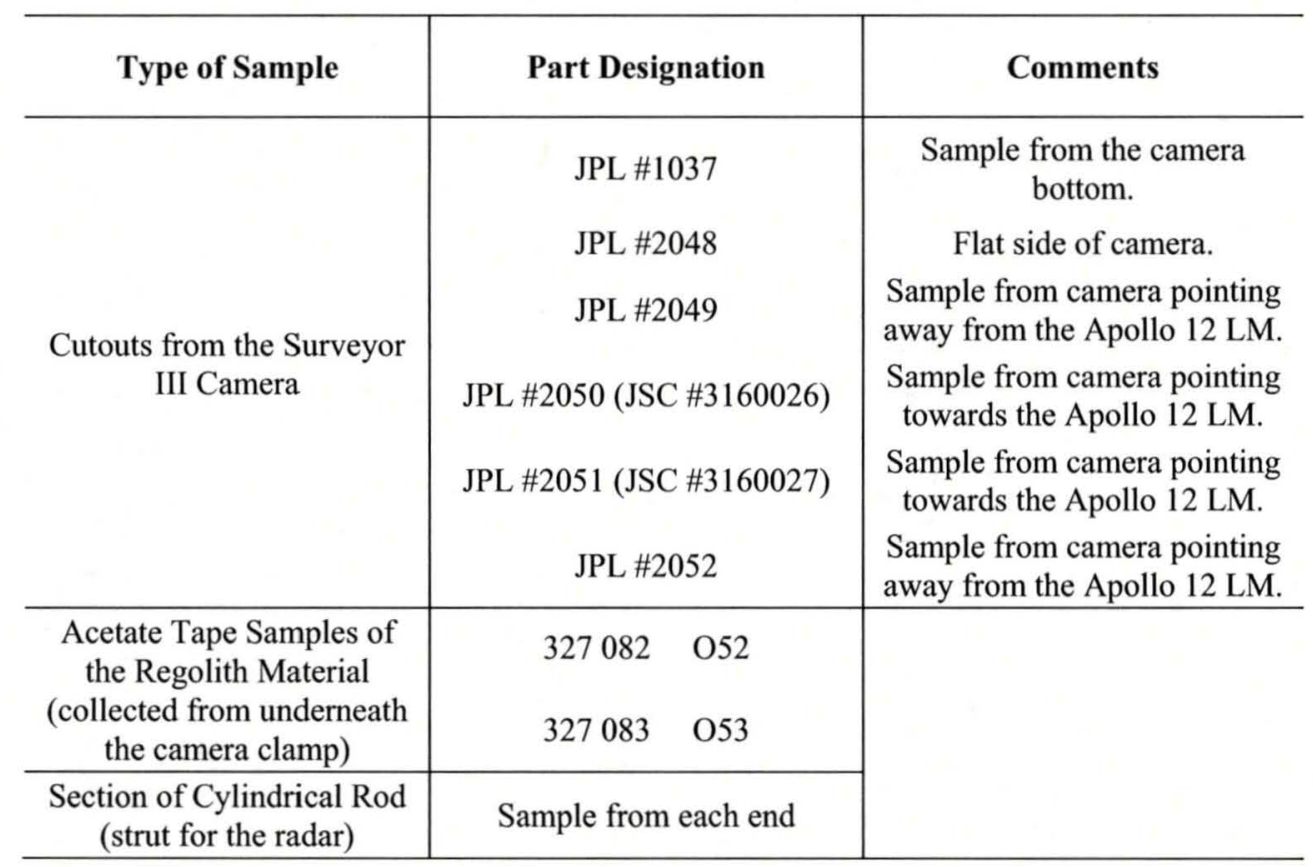

\section{PARTICLE MODELING AND SIMULATION}

\section{Shear Stress Simulations of LM Engine Plume Flyby}

Starting with a Fluent CFD simulation of the Apollo LM engine in a lunar-like environment (background pressure is artificially set to a small non-zero value in order to achieve 
convergence), three gas parameters are computed for every point in a $2 \mathrm{D}$ non-uniform spatial grid: gas density $\rho(k)$, gas temperature $T(k)$, and gas velocity $\mathbf{v}(k)$. Each CFD simulation and computed gas parameter output set corresponds to a specific engine height $h$ above the lunar surface. The CFD simulation generates gas parameter data at specific spatial points corresponding to the $x-y$ coordinates contained in the grid point array, $\mathbf{r}(k)$. Note that for the Fluent CFD cases considered in this report, vertical positions are described by the coordinate $x$ and horizontal positions are described by the coordinate $y$. Since the CFD generation of spatial points is based on algorithms which are used to minimize error in partial differential equations describing the laws of fluid mechanics, the grid points for all practical purposes are randomly distributed. Therefore, finding a specific point nearest a field point $x-y$ and its nearest neighbors, involves searching the entire $\mathbf{r}(k)$ array for $k=1 \ldots N$.

To compute the shear stress from the CFD output, the grid data is resampled along the lunar surface boundary at $\mathbf{r}_{m n}=(m \Delta x, n \Delta y)$ for $m=0,1,2$ and $n=0 \ldots N_{x}$. The shear stress is defined by:

$$
\tau \equiv \mu \frac{\partial v_{y}}{\partial x}
$$

where $\mu$ is the dynamic viscosity of the gas, $v_{y}$ is the horizontal component of the gas velocity along the horizontal surface boundary, and $x$ is the distance above the surface. The gas dynamic viscosity is a function of temperature and can be computed by Sutherland's formula approximation:

$$
\mu(T) \equiv \mu_{0} \frac{T_{0}+C}{T+C}\left(\frac{T}{T_{0}}\right)^{3 / 2} \quad,
$$

where the parameters $\mu_{0}, C$, and $T_{0}$ are dependent on the gas composition.

A discrete approximation to the shear stress of Equation (1) can be computed using the resampled CFD output:

$$
\tau_{n} \equiv \mu_{n} \frac{v_{y_{2, n}}-v_{y_{0, n}}}{2 \Delta x}
$$

where

$$
\mu_{n} \equiv \mu_{0} \frac{T_{0}+C}{T_{1, n}+C}\left(\frac{T_{1, n}}{T_{0}}\right)^{3 / 2}
$$

An equivalent shear velocity (sometimes referred to as saltation velocity) can be computed from Equation (3) and the resampled gas density:

$$
u_{n} \equiv\left(\frac{\tau_{n}}{\rho_{1, n}}\right)^{1 / 2}
$$

\section{SIMULATION RESULTS}

Shear stress along the surface has been computed for the five cases generated by Fluent CFD: $h$ $=5,10$, and $20[\mathrm{ft}]$ and $h=25$ and $45[\mathrm{~m}]$. The shear stress is computed and plotted for these 
five cases in Figure 16. The shear stress in this figure was generated with $\Delta x=0.001[\mathrm{~m}]$ in Equation (3).

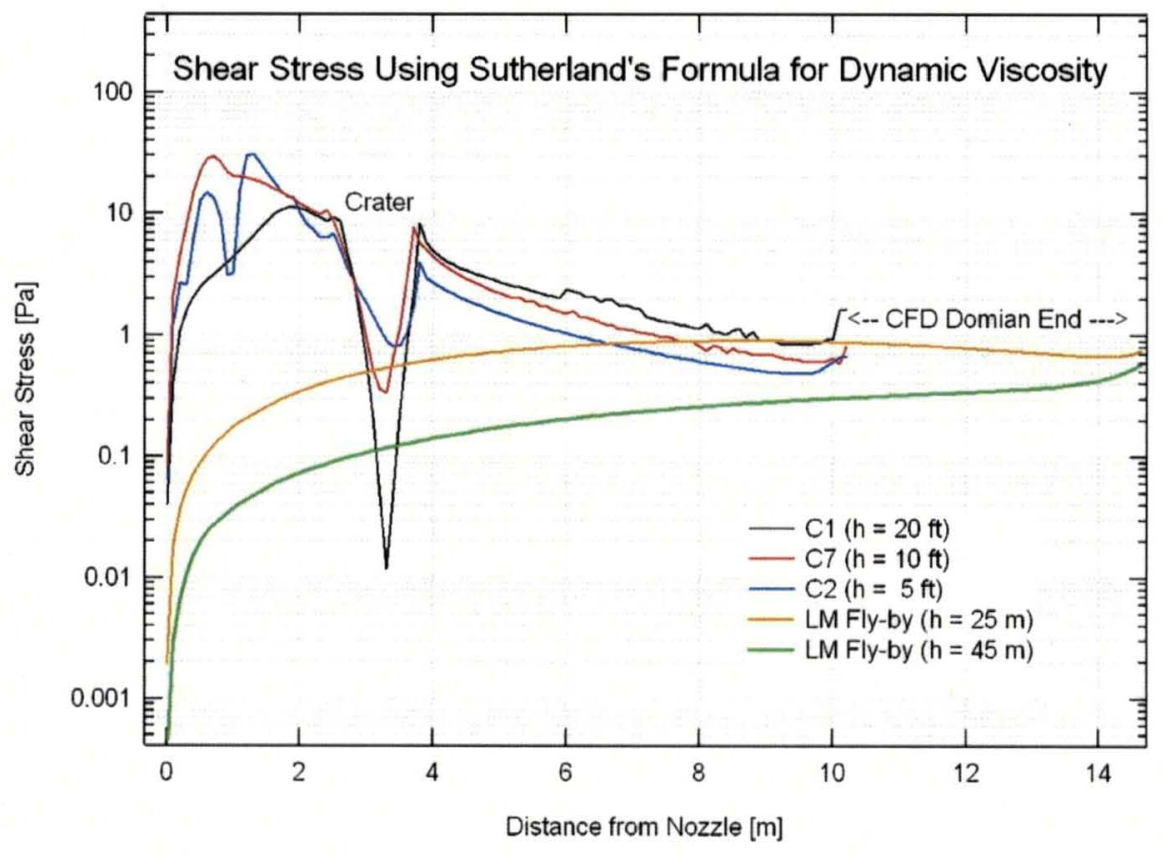

Figure 5: Shear stress along the $x=\Delta x$ surface for five cases generated by Fluent CFD: $h=5,10,20,25$, and 45 [ft].

\section{Threshold Shear Stress Velocity}

Starting with the approach of Sagan (1990), the threshold shear stress velocity is:

$$
u^{*}=\frac{1}{D}\left|\alpha_{0} \eta-\alpha_{1} \frac{\eta^{2}}{\Gamma}-\alpha_{4} \Gamma\right|
$$

where,

$$
\Gamma \equiv\left(\phi_{2}+\left(\phi_{2}^{2}-\phi_{1}^{2}\right)^{1 / 2}\right)^{1 / 3}
$$

and,

$$
\phi_{1} \equiv \alpha_{2} \eta^{3} \quad \phi_{2} \equiv \alpha_{3} \beta D^{1 / 2} \eta \quad .
$$

The gas kinematic viscosity is the gas dynamic viscosity divided by its density: $\eta=\mu / \rho$. With Equation (5) and its variables expressed in SI units, the constant coefficients are given in Table 2. 
Table 2. Coefficients in Equations (5) and (7).

\begin{tabular}{c|c}
\hline$\alpha_{0}$ & $2 / 15$ \\
$\alpha_{1}$ & 8.3995 \\
$\alpha_{2}$ & 250000 \\
$\alpha_{3}$ & 843750 \\
$\alpha_{4}$ & 0.0021165 \\
\hline
\end{tabular}

The result in Sagan (1990) was greatly simplified with the assumption that the Reynolds number is much less than 1: $\quad$ or $\quad$. Equations (5) through (7) do not make that assumption. The threshold shear stress velocity of Equation (5) can be converted into a threshold shear stress, similar to that of Equation (5):

The cohesion force (interparticle force) in Sagan (1990) is approximated as:

where again, Equation (9) and its variables are all expressed in SI units. Sagan (1990) used a value of $\beta=6 \times 10^{-7}$ to represent the cohesive force of particles on the surface of Triton. To simulate a zero cohesion force, $\beta$ is set equal to zero.

\section{SIMULATION RESULTS}

Figure 17 shows the trajectory simulation results: the radial distance traveled by particle from ground track position as a function of particle diameter. Circles represent different starting points, both $x$ and $y$, while the solid line is the average maximum value of the individual trajectories. Note that there is a notable cut-off as the particle size approaches $100 \mu \mathrm{m}$.

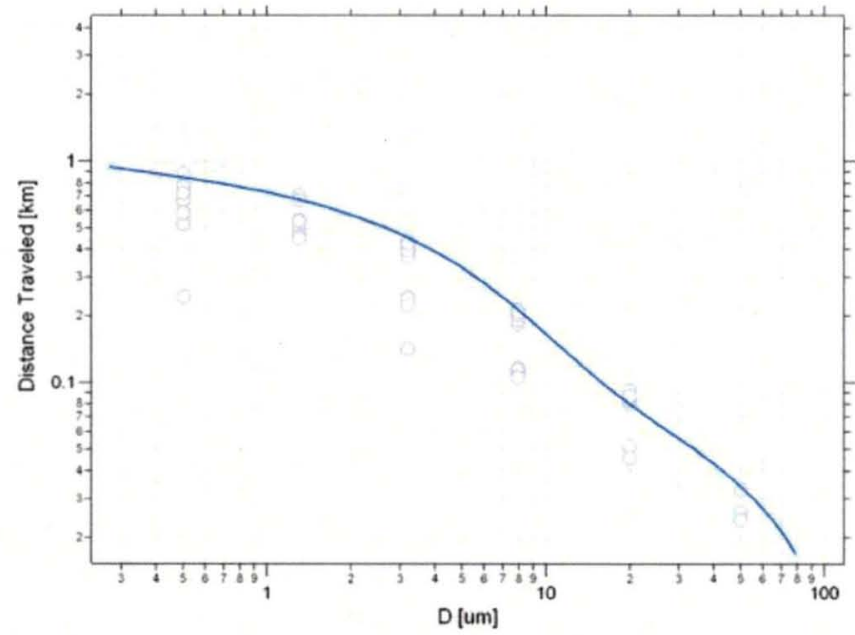

Figure 6: Radial distance traveled by particle from ground track position as a function of particle diameter for $h=45 \mathrm{~m}$. Circles represent different starting points, both $x$ and $y$. Solid line is the average maximum value of the individual trajectories. 
Figure 18 shows post-processed results of a Fluent CFD simulation corresponding to the Apollo 12 LM flyby at $h=45[\mathrm{~m}]$. Note that the actual height of the closest approach distance from the LM ground track to the Surveyor III site is approximately $h=65[\mathrm{~m}] . \quad(h=65[\mathrm{~m}]$ Fluent CFD results were not available during the project period). Referring to Figure 18, the left axis and blue line represents the radial distance traveled by a particle from the ground track position. The shaded portion represents all particles whose horizontal trajectory distance is equal to or greater than the distance to the Surveyor spacecraft $(R=109[\mathrm{~m}])$.

The right axis corresponds to the difference in shear stress, Equation (3) and threshold shear stress, Equation (8), indicating the region where lift may occur without the need of particle collisions to initiate a lift process. The zero cohesion force case is shown by the green line and green shading. Sagan's cohesion force, using $\beta=6 \times 10^{-7}$, is shown by the brown line and shading.

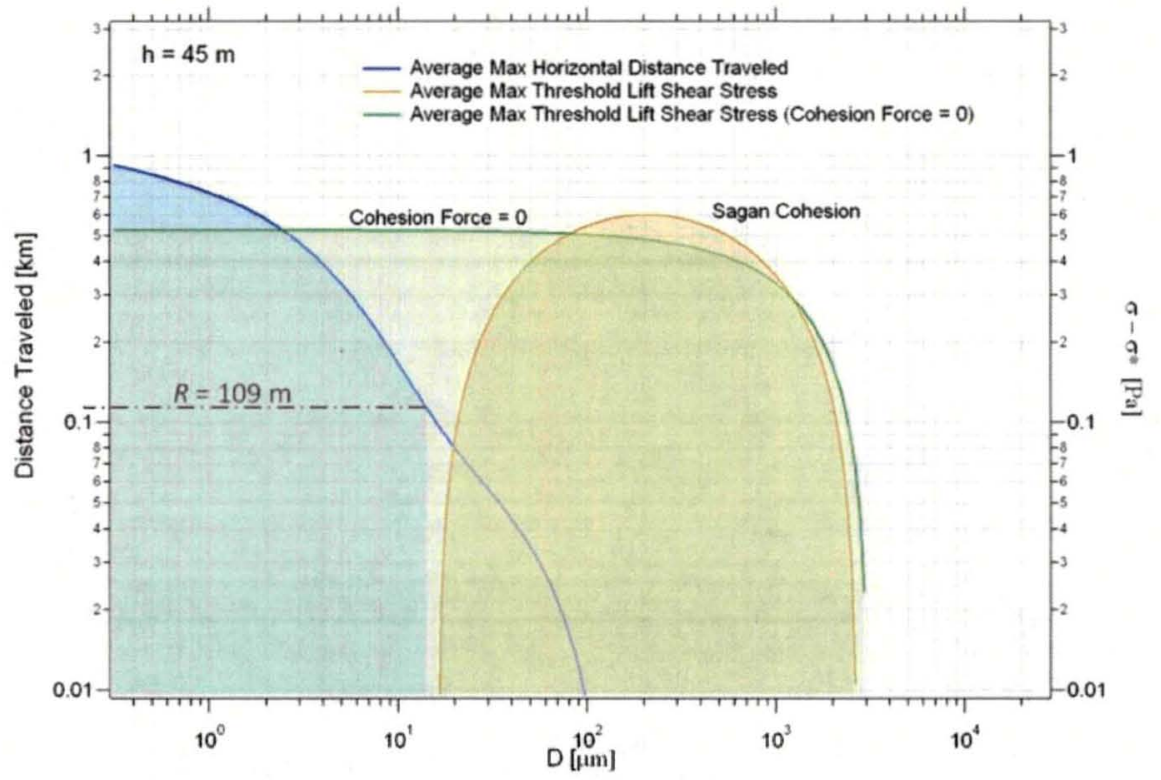

Figure 7: LM Flyby simulation at $h=\mathbf{4 5}[\mathrm{m}]$. Left axis: (blue line) radial distance traveled by particle from ground track position. Right axis: (green and brown lines) region where shear stress is greater than threshold shear stress, resulting in particle lift for zero cohesion force (green line) and for Sagan's cohesion force (brown line).

\section{Discussion}

Based on particle trajectory simulations for the $h=45 \mathrm{~m}$ case (the $h=65 \mathrm{~m}$ case was not completed, possibly due to numerical convergence problems), dust reaches the Surveyor III site from the LM flyby closest approach $(R=109 \mathrm{~m})$. Particle sizes up to $D=13$ um reach the Surveyor III with velocities up to $130 \mathrm{~m} / \mathrm{s}$. Particles sizes $D>13 \mathrm{um}$, are also ejected, but fall back to the surface before traversing the complete $109 \mathrm{~m}$ distance to the Surveyor. Particles in the size range of $17<D<2600 \mu \mathrm{m}$ can be lifted by the gas shear stress, based on the $h=45 \mathrm{~m}$ Fluent CFD case. According to the plots in Figure 18, there is no particle size range that shows an overlap between the trajectory distance and threshold shear stress for $R=109 \mathrm{~m}$. Inspecting the plot in more detail, particles of $D=20 \mu \mathrm{m}$ would reach a distance of $R=80 \mathrm{~m}$. 
Sagan's cohesion force (Iversen,1982) predicts interparticle cohesion forces on the order of $\mathrm{nN}$ for particles in the range of $10-100 \mu \mathrm{m}$. Sagan's cohesion force is about a 1000 times smaller than the cohesion force predicted by Walton (2008), which predicts $\mu \mathrm{N}$ particle pull-off forces (see Figure 19). Even for the small Sagan cohesion force $(\sim \mathrm{nN}$ for 10-100 $\mu$ m particles), particles do not make it to the Surveyor III site, unless the cohesion force is much smaller (maybe a factor of 10 smaller would do it). But a factor of 1000 larger would certainly decrease the chance of particle spray from the LM flyby.

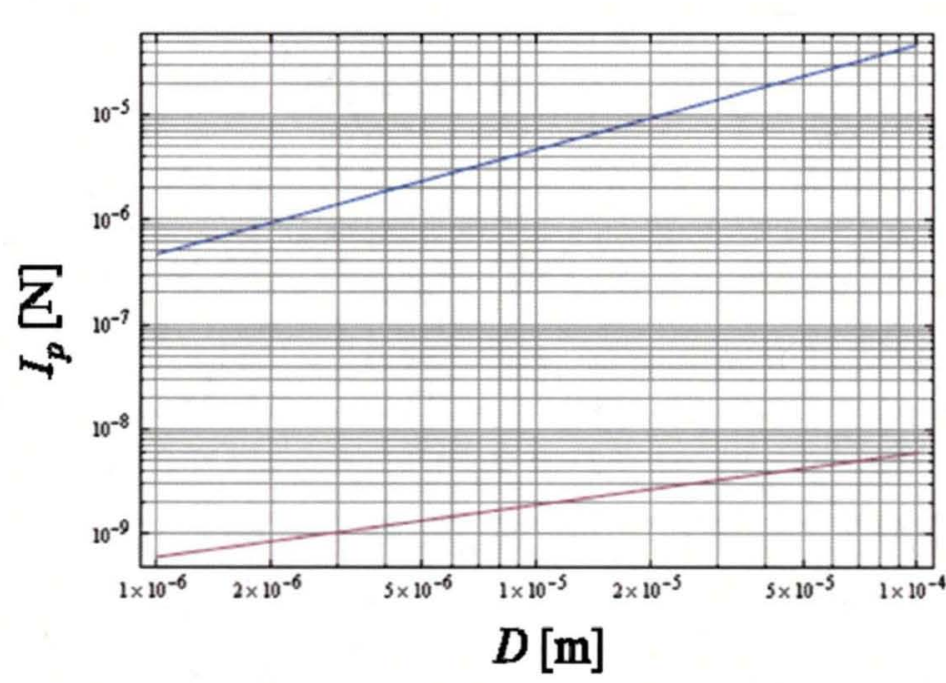

$$
\begin{aligned}
& F_{s p}=2 \pi \gamma D \\
& \gamma=0.075\left[\mathrm{~J} / \mathrm{m}^{2}\right] \\
& \text { Wolton O.R., "Review of Adhesion Fundeanentuls for } \\
& \text { Micron-Scale Particles", Powder and Particle Joumal, 26, } \\
& \text { 2008, pp. 129-141. }
\end{aligned}
$$$$
I_{p}=K D^{3-n}
$$$$
K=6 \times 10^{-7}\left[\mathrm{~N} / \mathrm{m}^{1 / 2}\right]
$$$$
n=5 / 2
$$

Fversen, J.D, BR. White, "Saltration Threshold on Earth, Mars, and Venms", Sedlanentology, 29, 1982, pp. 11 l-119.

Figure 8: Comparison between Iverse (1982) interparticle cohesion forces and cohesion pull-off force predicted by Walton (2008).

\section{DARCY'S LAW}

Darcy's Law describes the volume flow rate $Q$ of a gas or liquid of viscosity $\mu$ through a solid porous medium of permeability $\kappa$, due to a pressure gradient over a length $\Delta L$ :

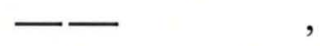

where $A$ is the cross-sectional area of the flow volume and $\Delta P / \Delta L$ is the pressure gradient. Darcy's Law can be used to describe the portion of gas that is injected into the soil immediately beneath the rocket nozzle. Since $Q$ in Equation (D1) can be replaced by the gas velocity $v(t)$ scaled by $A$, the initial velocity at $t=0$ is:

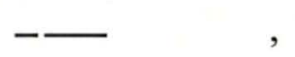

Immediately before engine cutoff, the pressure on the surface due to the lander's rocket gas impingement at $t=0$ can be approximated as: 
where $M$ is the mass of the lander, $g$ is acceleration due to lunar gravity, and $A$ is the area on the surface over which the pressure is acting. Combining Equations (D2) and (D3):

$$
v_{0}=-\frac{\kappa M g}{\mu \Delta L A} \quad,
$$

The trajectory of regolith particles lifted upwards from the surface after engine cutoff due to the release of plume gas trapped in the soil can be computed by considering Newton's second law of motion, $F=m a$. $F$ for can be expressed as the gas pressure at the surface due to the trapped gas below as, $\rho v^{2}(t) / 2$, where $\rho$ is the gas density. The term ma can be expressed as $(\rho A L) d v(t) / d t$, which then leads to:

$$
\frac{d v(t)}{d t}=-\frac{v(t)^{2}}{2 L}
$$

where the minus sign is needed because of velocity decreasing. The solution to Equation (D5) is:

$$
v(t)=\frac{v_{0}}{v_{0} t / 2 L+1} \quad .
$$

Equation (D5) is an approximation the velocity of a particle lifted from the surface due to the Darcy effect, immediately following engine cutoff.

A single particle trajectory can be obtained by computing the position as a function of time by evaluating the integral of velocity from 0 to $t$ :

$$
y(D, t)=\int_{0}^{t}\left(v\left(t^{\prime}\right)-v_{T}(D)\right) d t^{\prime},
$$

where $y(D, t)$ is the vertical position of the particle and $v_{T}(D)$ is its terminal velocity in the gas flow. Note the particle diameter dependence of the terminal velocity term. The above integral can be evaluated as:

$$
y(D, t)=2 L \ln \left(v_{0} t / 2 L+1\right)-v_{T}(D) t \quad,
$$

The terminal velocity term is due to the drag on the particle by the gas and the pull of lunar gravity. Since the gas density is very small as compared to the particle density $\rho_{p}$, the terminal velocity $\nu_{T}(D)$ depends only on gas viscosity $\mu(T)$, as given by Equation (2), as well as gravity $g$ and particle diameter $D$ :

$$
v_{T}(D)=\rho_{p} g D^{2} / 18 \mu(T)
$$

To demonstrate the ideas described above, Apollo landing videos can be used. Figure D1 shows a view captured by the Apollo 14 cockpit camera immediately after engine cutoff. The luminosity value $L(t)$ is found in two regions of the image at $t=0$ and again at $t=34 \mathrm{~s}$. The right histograms corresponds to a region imaged inside of the LM, part of the window frame. The histograms on the left correspond to a shadowed region on the lunar surface partly obscured by dust. Figure D2 plots the normalized relative luminosity, $L_{N}(t)=\left(L(t)-L_{\infty}\right) / L_{0}$, over several frames. In this case, $L_{0}=L(0)$ and $L_{\infty}=L(34)$. For comparison, a dust particle falling freely under lunar gravity from a height $y_{0}=10 \mathrm{~m}$ is shown, where $y(t)=y_{0}-g t^{2} / 2$. Also plotted in 
Figure D2 is Equation (D8) for several values of particle diameter with a temperature $T=250 \mathrm{~K}$, $A=1 \mathrm{~m}^{2}, \Delta L=0.2 \mathrm{~m}, \kappa=10 \mu \mathrm{m}^{2}, \rho_{p}=3100 \mathrm{~kg} / \mathrm{m}^{3}$, and $M=14$ metric tons.

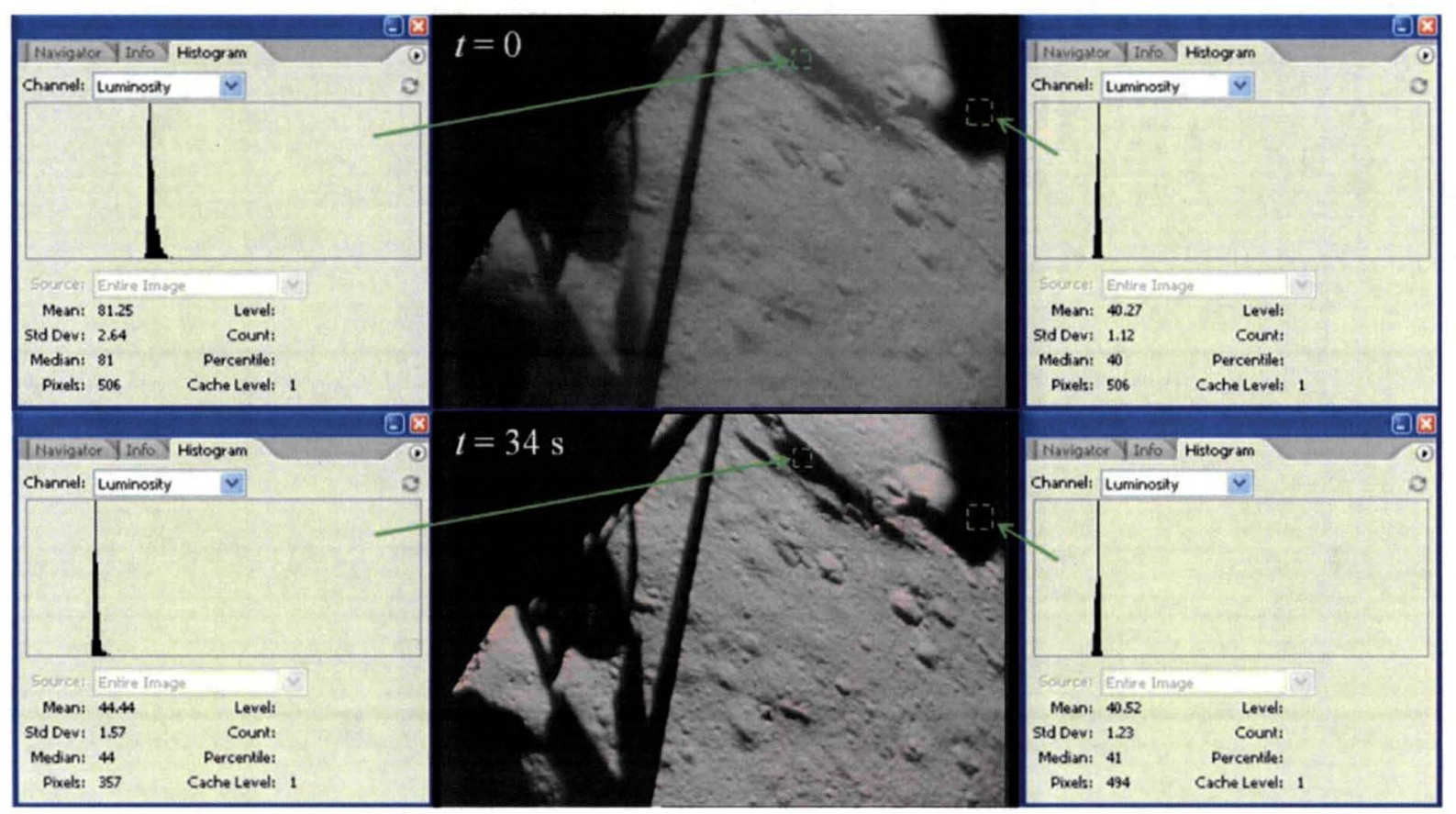

Figure 9: Luminosity measurements of Apollo 14 landing videos following engine cutoff.

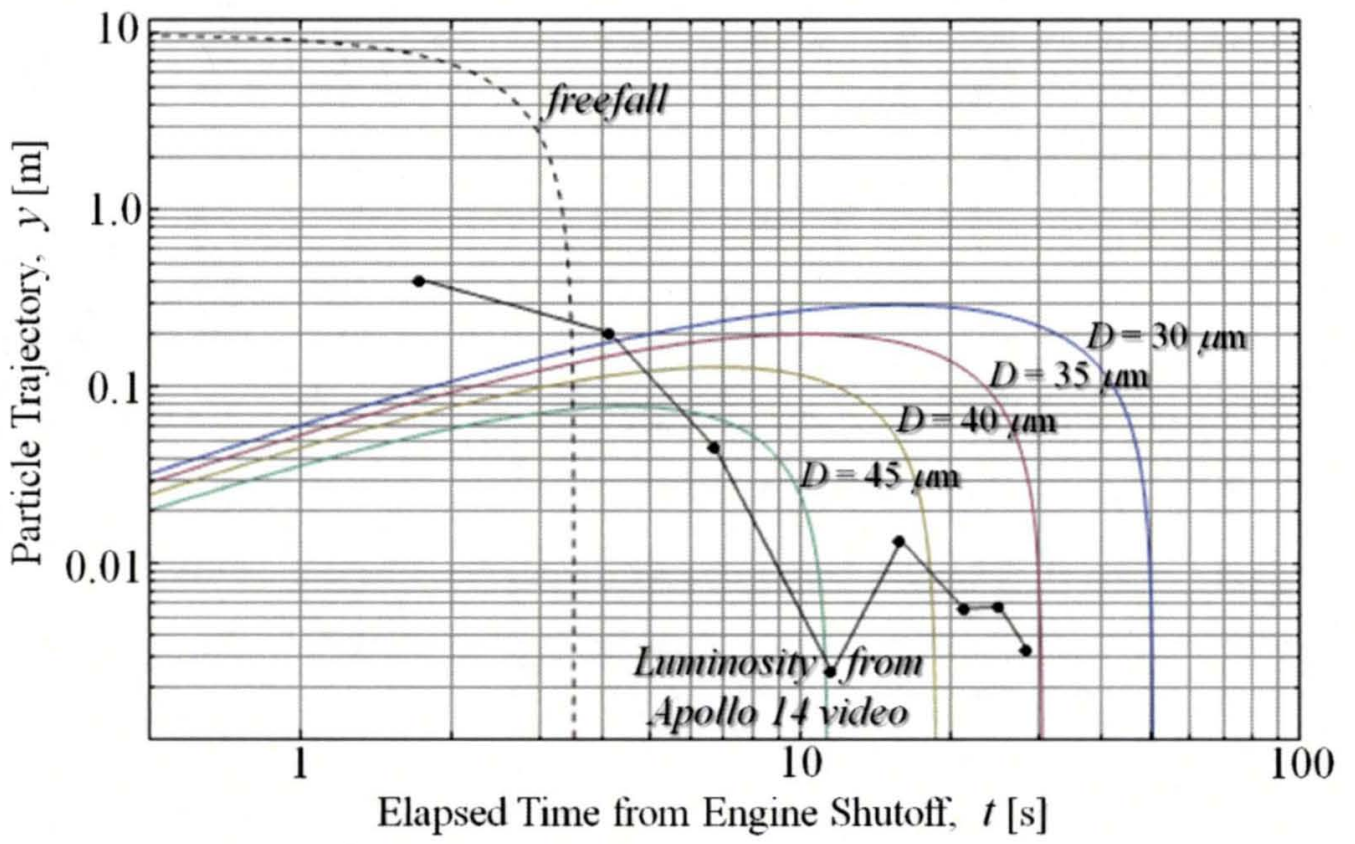

Figure 10: Freefall and Darcy law particle trajectories compared to luminosity. 


\section{Discussion}

The first conclusion that can immediately be reached by inspection of Figure D2 is that the time required for dust clearing to occur is longer by an order of magnitude then would be explained by freely falling dust under lunar gravity. The same is true for dust under the influence of a static electric field since the electric field term would more likely decrease the clearing time as opposed to an unlikely balance of electric and gravity forces leading to a longer clearing time.

Dust propelled vertically by the Darcy effect could circumstantially explain the dust clearing since there are a range of conditions where Equation (D8) matches the clearing time corresponding to the luminosity values measured in the Apollo 14 video. Ignoring the gross assumptions that led to Equation (D8), the Darcy Law simulations do not show the dust travelling high from the surface, which for Figure D2 is only in the $10-20 \mathrm{~cm}$ range. This may however be consistent with the Apollo videos since the main landing dust plume (before engine cutoff) is believed to be contained within a three degree sheath radially centered about the nozzle, which for a distance of $5 \mathrm{~m}$ form the nozzle corresponds to dust only up to $25 \mathrm{~cm}$ above the surface. The dust viewed by the videos before and after engine cutoff, is primarily seen as a haze over the surface. Another interesting feature in Figure D2 is the dip in the luminosity. Since it is only a single point, it is unwise to declare this an important feature without additional image analysis.

\section{SEM STUDIES}

Samples were analyzed via scanning electron microscopy (SEM) and Electron Dispersive $\mathrm{X}$-Rays (EDX) to visually and chemically study several of the Surveyor III samples.

\section{XPS ANALYSIS}

X-ray photoelectron spectroscopy (XPS) analysis was performed on areas from 3 cut-outs from the Surveyor III camera, namely; parts \#2048, \#2050, and \#2051. Visual observation on the parts showed areas of differing discoloration. As XPS is a very surface sensitive technique, analysis was performed to determine any chemical differences between the areas to explain the apparent discoloration. The areas of analysis are shown in the figures for each part respectively.

The XPS analysis was performed on a Thermo Scientific K-Alpha spectrometer. The samples were mounted with care so as to not introduce any surface contamination by handling. The samples were pumped down to a background pressure of $3 \times 10^{-9}$ torr. The x-rays used were from an $\mathrm{Al} \mathrm{K \alpha}$ source with an energy of $1486.6 \mathrm{eV}$. A low energy electron flood gun was utilized to prevent charging of the surface. A spot size of $400 \mu \mathrm{m}$ was used for each analysis point and wide survey scans were taken to detect all elements of interest. The mean escape depth of the emitted photoelctrons is approximately $50-100 \AA$, depending upon the element, and so XPS is a very surface sensntive technique. The areas under the peaks of the detected elements were measured and the relative atomic concentrations were calulated using sensitivity factors provided by the instrument manufacturer. The accuracy of quantification is approximately $+/-$ $5 \%$ of the determined values. In the approximate areas illustrated in the Figures 21 and 25, thirteen (13) random analysis points were taken and the mean value calculated with the standard 
deviation. For sample \#2050 (Figs. 22 and 23), a series of overlapping analysis points were taken in a linescan across the dark shadow region outside the bolt hole.

\section{Sample \#2048}

The sample is ahown in Fig. 21, and the results of the analysis are shown in Table 3.

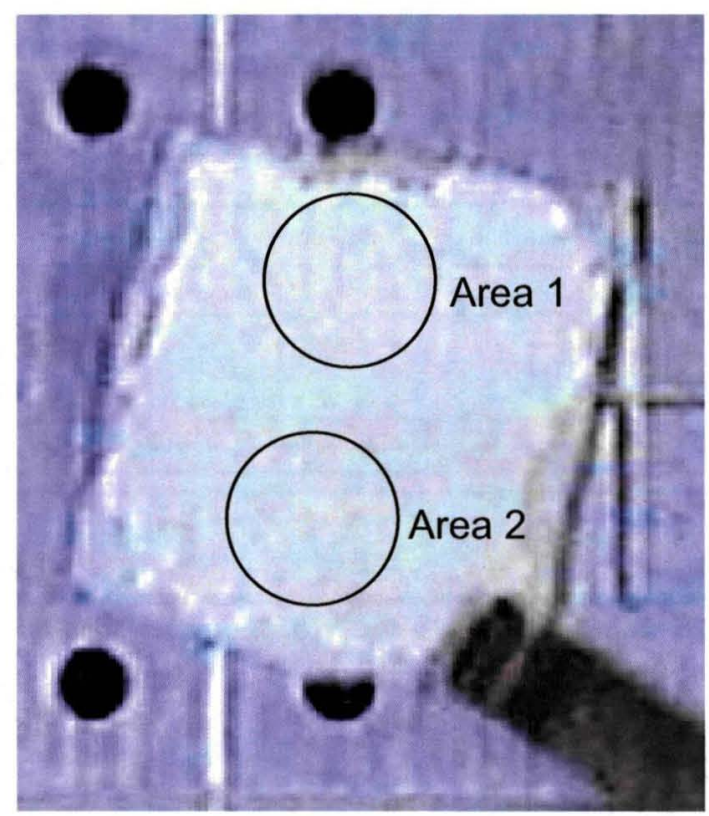

Figure 21: Sample \# 2048 showing areas of analysis in the light (Area 1) and dark (Area 2) areas.

Table 3: Relative atomic \% of elements in Areas 1 and 2 of sample \#2048.

\begin{tabular}{|c|c|c|c|c|c|c|c|c|c|c|c|l|}
\hline & O1s & K2p & Si2p & Al2p & Na1s & Mg1s & C1s & S2s & Fe2p & Cl2p & F1s & \\
\hline Area 1 & 58.42 & 9.08 & 16.30 & 3.19 & 0.57 & 0.33 & 11.51 & 0.42 & 0.05 & 0.07 & 0.08 & Mean \\
\cline { 2 - 13 } (lighter) & 0.12 & 0.08 & 0.52 & 0.21 & 0.11 & 0.14 & 0.68 & 0.05 & 0.06 & 0.10 & 0.11 & SD \\
\hline $\begin{array}{c}\text { Area 2 } \\
\text { (darker) }\end{array}$ & 54.52 & 9.70 & 14.29 & 2.25 & 0.67 & 0.69 & 16.24 & 0.88 & 0.21 & 0.43 & 0.40 & Mean \\
\cline { 2 - 12 } & 0.19 & 0.42 & 0.04 & 0.10 & 0.57 & 2.55 & 0.21 & 0.08 & 0.01 & 0.40 & SD \\
\hline
\end{tabular}

The main difference between the lighter and darker areas is a notable increase in the $\mathrm{Mg}$, $\mathrm{Fe}, \mathrm{Fe}, \mathrm{C}, \mathrm{S}, \mathrm{Cl}$, and $\mathrm{F}$ concentrations. The white paint originally applied to the Surveyor III craft was reported to be composed of aluminum silicate pigment with a potassium silicate binder (Immer, 2010). The Al, Si, O, and $\mathrm{K}$ concentrations can therfore be attributed to the paint coating. Analysis of Apollo 12 regolith collected during the mission, showed after $\mathrm{Al}$ and $\mathrm{Si}$ oxides, the next predominant compounds were $\mathrm{Fe}, \mathrm{Mg}$, and $\mathrm{Ca}$ oxides (Heiken, 1991). Unfortunately, in the above analysis, $\mathrm{Ca}$ was not detected due to the signal-to-noise of the 
spectra had not been optimised, however, the significant increase in the $\mathrm{Fe}$ and $\mathrm{Mg}$ concentrations strongly indicate the presence of lunar regolith in the darker area. The two most abundant minerals in the Apollo 12 regolith after agglutinates, were pyroxene and olivine (Heiken, 1991) that have the chemical formulas, $\mathrm{XY}(\mathrm{Si}, \mathrm{Al})_{2} \mathrm{O}_{6}$ (where $\mathrm{XY}=\mathrm{Ca}, \mathrm{Na}, \mathrm{Fe}, \mathrm{Mg}$ ), and $(\mathrm{Mg}, \mathrm{Fe})_{2} \mathrm{SiO}_{4}$, respectively. The data above also correlates with the presence of these two minerals.

The presence of $\mathrm{C}, \mathrm{F}, \mathrm{S}$, and $\mathrm{Cl}$ indicate contamination of the sample, as had been previously reported reflecting the extensive use of fluorocarbons during the Apollo missions and post-mission sample handling (Goldberg, 1976).

\section{Sample \#2050}

For this sample, a shadowed region to one side of a bolt hole was observed, as shown in Fig. 22. The white region is unexposed paint that was under a washer. In order to determine the nature of this darkened area, survey scans were performed in an overlapping series (linescan) from the white area out through the shadowed darker area to the lighter area. The red line in Fig. 22 shows the approximate path of the linescan. The actual analysis points are shown in the higher magnification photograph in Fig.23.

For these analyses, the acquisition time was increased to improve the signal-to-noise ratio in the spectra so that the Ca peaks were detected and could be quantified. The data was plotted as atomic concentration as a function of the linescan across the region, and is shown in Fig. 24. In Fig 24a, the entire data set is included, and in Fig. 24b, the Y-axis was expanded to better show the variation of the minor elements. 


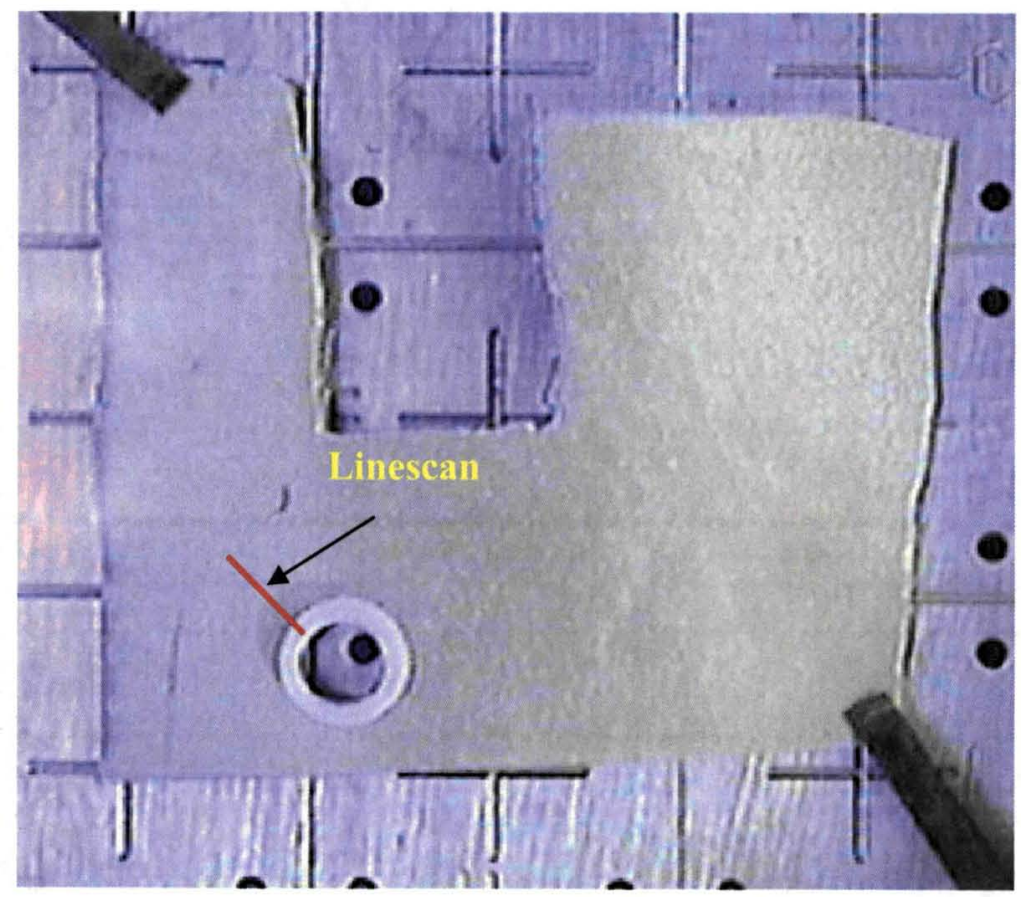

Figure 22: Sample \# 2050 showing area of linescan across the dark shadow near hole.

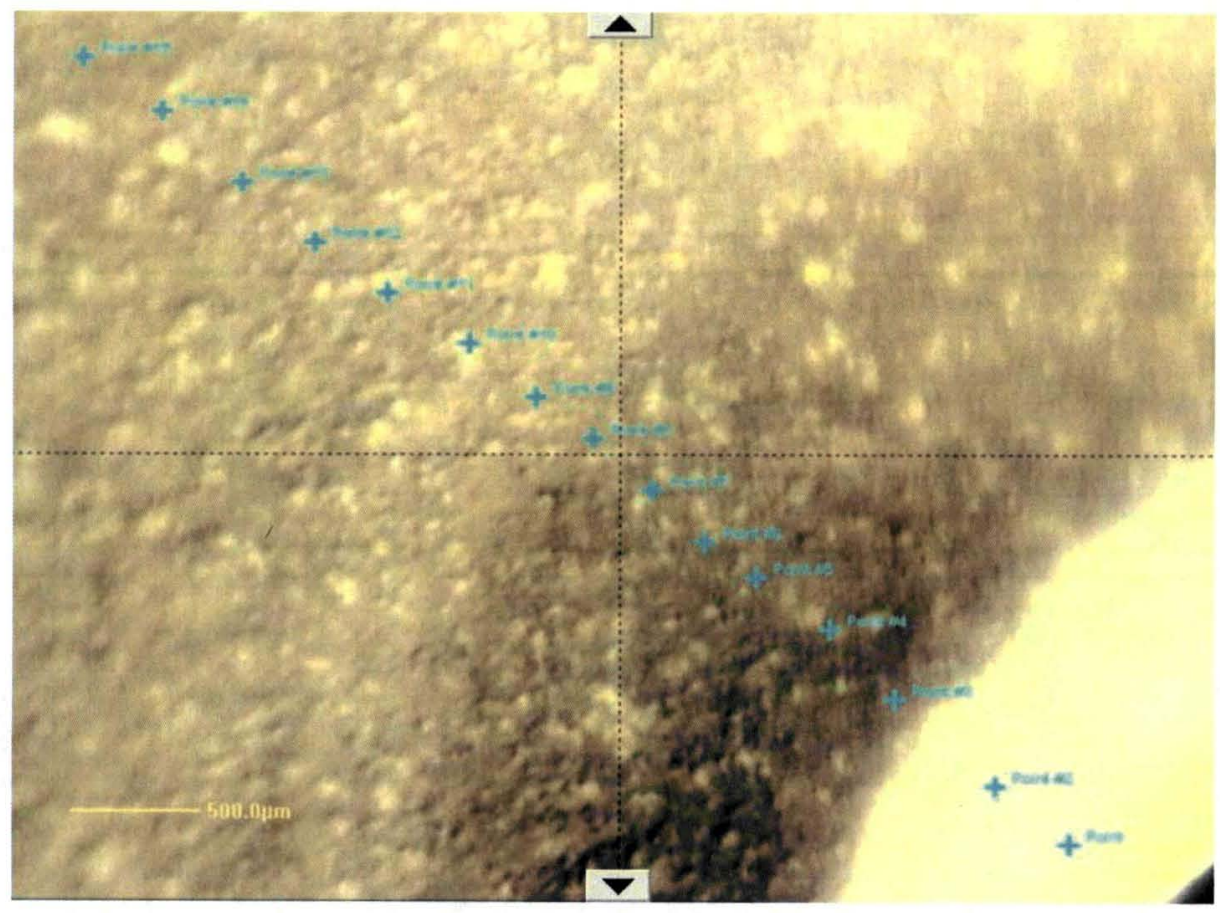

Figure 23: Sample \# 2050. The linescan analysis started at bottom right. Each analysis point was a 400 um spot size and each point overlapped. 


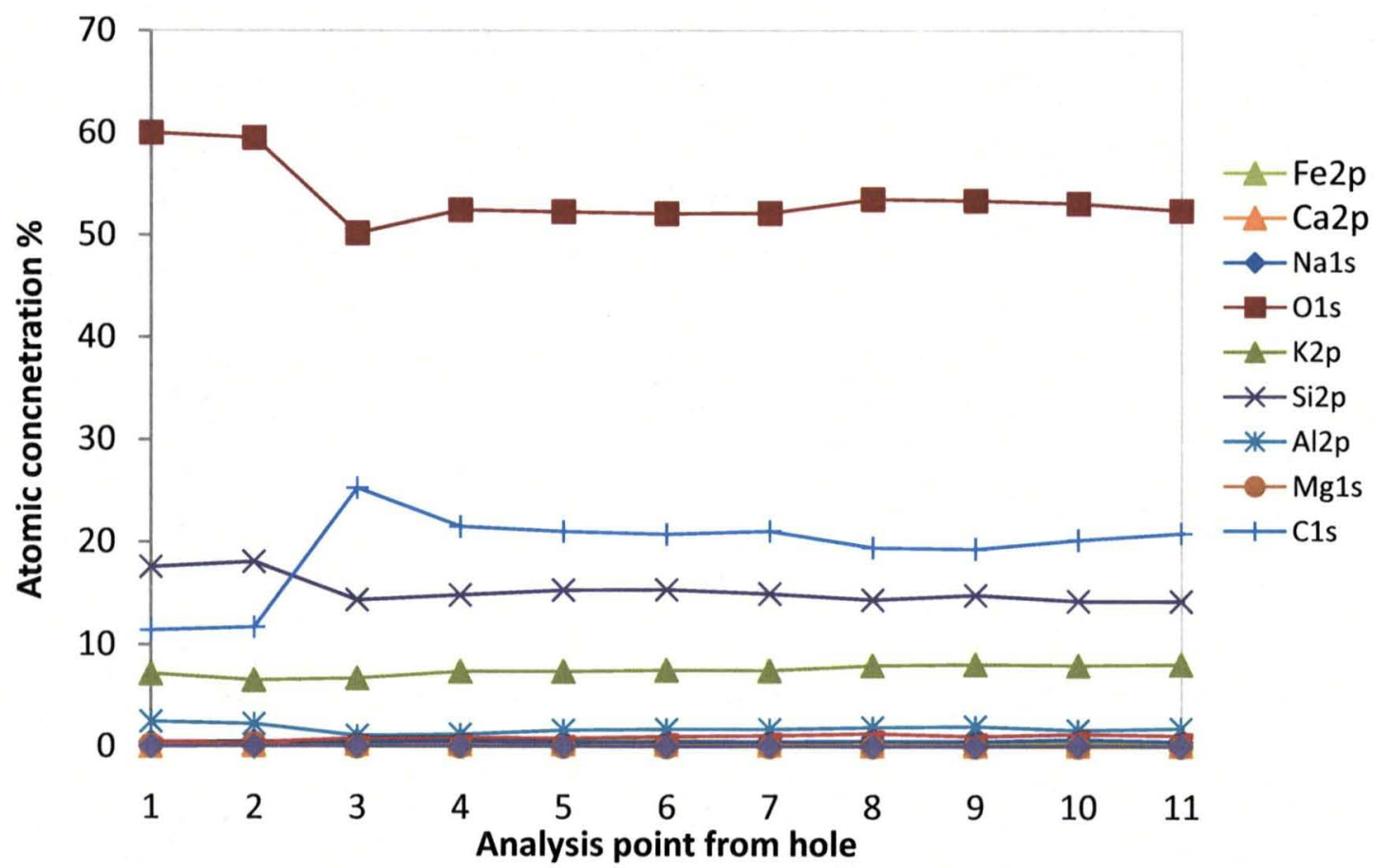

Figure 24a: Relative atomic concentrations across shadowed section in Fig. 23.

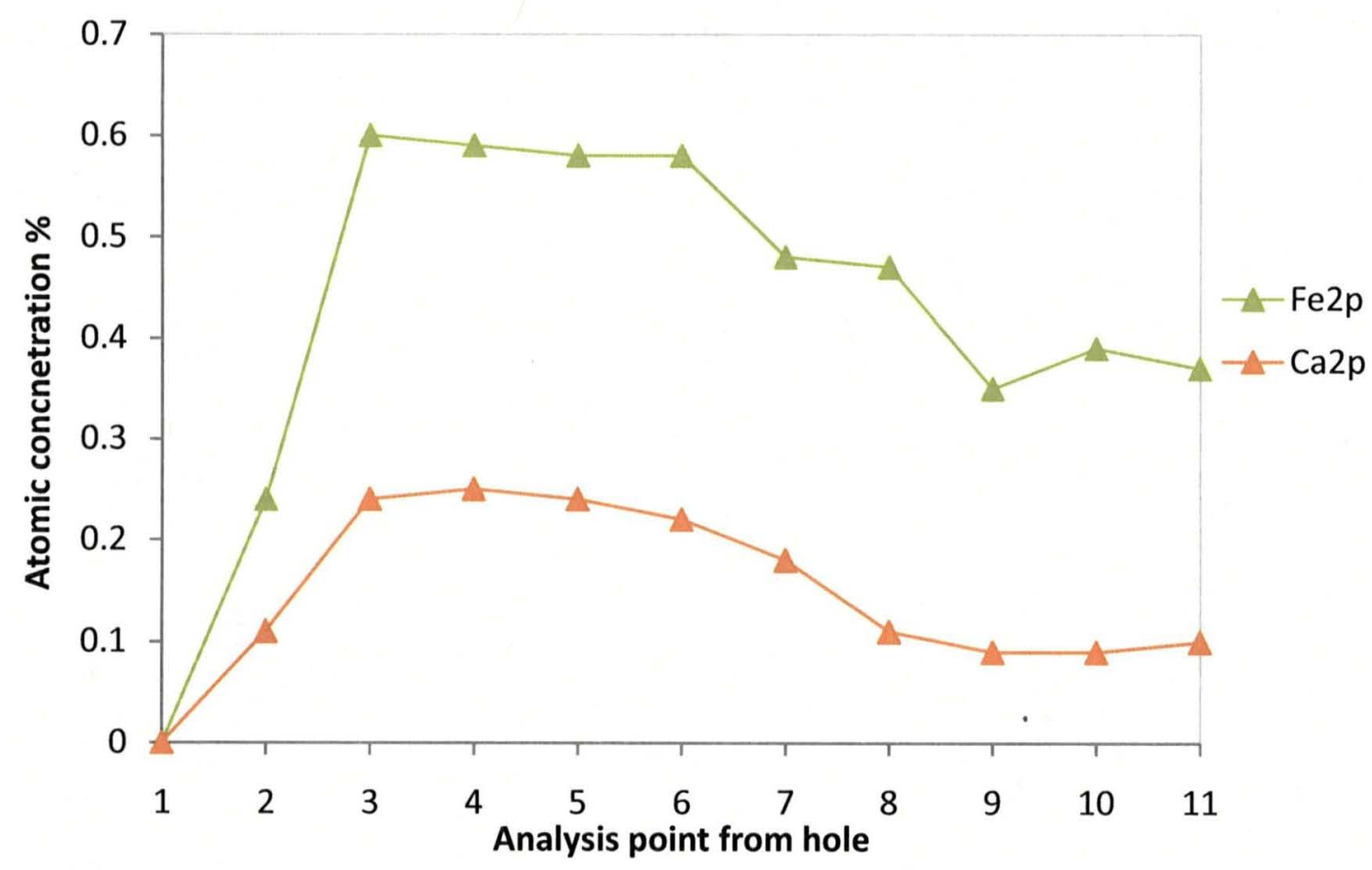

Figure 24b: Relative atomic concentrations of $\mathrm{Fe}$ and $\mathrm{Ca}$ across shadowed section in Fig. 23. 
In Fig. 24a the higher concentrations of $\mathrm{Al}, \mathrm{Si}$, and $\mathrm{O}$ are expected in the white area that was under the washer which are indicative of the paint coating. The $K$ concentration does not vary much across the linescan, but as $\mathrm{K}$ is also a component of feldspar (orthoclase) as well as the paint pigment, any variation may not be obvious. The $\mathrm{C}$ concentration peaks at the edge of the dark shadow region, and is then steady acorss the rest of the linescan. From Fig. 23, the dark shadow region encompasses the analysis points 3 to 8 . Expanding the Y-axis in Fig. 24a, as shown in Fig. 24b, and just including the lunar elements $\mathrm{Fe}$ and $\mathrm{Ca}$, an enrichment of these are clearly observed indicating the dark shadow region indeed contains lunar regolith.

\section{Sample \#2051}

For this sample, three distinct area were analyzed. Thirteen random analysis points were taken within each of the three circled areas shown in Fig. 25. Again for this sample, the acquisition times were optimised for maximum signal-to-noise ratio for detection and quatification of all elements. The relative atomic concentration were calculated and the mean value with the standard deviation are presented in Table 4.

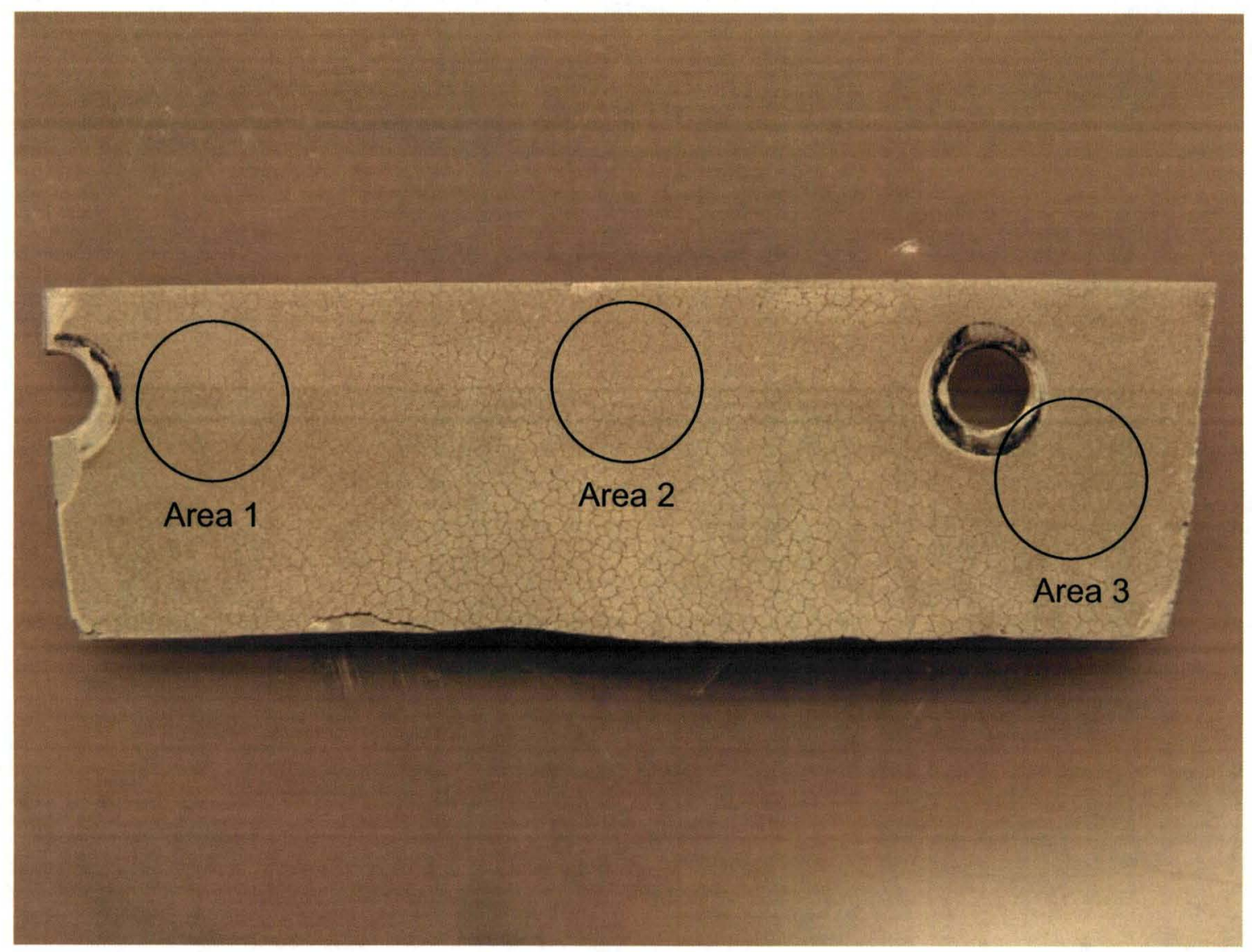

Figure 25: Sample \# 2051 showing areas of analysis. 
Table 4: Relative atomic \% of elements in Areas 1, 2, and 3 of sample \#2051.

\begin{tabular}{|l|c|c|c|c|c|c|c|c|c|c|c|c|l|}
\hline & O1s & K2p & Si2p & Al2p & Na1s & Mg1s & C1s & S2s & Fe2p & F1s & C12p & Ca2p & \\
\hline \multirow{2}{*}{ Area 1 } & 53.73 & 9.37 & 13.69 & 2.11 & 0.72 & 0.20 & 18.09 & 0.93 & 0.45 & 0.40 & 0.19 & 0.14 & Mean \\
\cline { 2 - 15 } & 2.40 & 0.37 & 1.09 & 0.29 & 0.09 & 0.04 & 3.15 & 0.18 & 0.08 & 0.04 & 0.04 & 0.20 & $S D$ \\
\hline \multirow{2}{*}{ Area 2 } & 55.33 & 9.77 & 15.77 & 1.29 & 0.62 & 0.30 & 15.49 & 0.38 & 0.32 & 0.34 & 0.17 & 0.24 & Mean \\
\cline { 2 - 14 } & 5.01 & 0.94 & 2.27 & 0.03 & 0.10 & 0.31 & 7.31 & 0.30 & 0.04 & 0.24 & 0.04 & 0.17 & $S D$ \\
\hline \multirow{2}{*}{ Area 3 } & 56.92 & 9.68 & 14.97 & 1.85 & 0.82 & 0.11 & 13.74 & 0.72 & 0.38 & 0.47 & 0.19 & 0.18 & Mean \\
\cline { 2 - 14 } & 2.37 & 0.04 & 0.21 & 0.34 & 0.16 & 0.06 & 2.04 & 0.17 & 0.01 & 0.19 & 0.06 & 0.02 & $S D$ \\
\hline
\end{tabular}

For this sample, within the error of measurement, little compositional difference was observed across the sample between the three areas. However, the presence of $\mathrm{Fe}, \mathrm{Ca}$, and $\mathrm{Mg}$ confirms the presence of lunar regolith on the sample.

As a final analysis, narrow scans of the C, K, F, and Fe peaks were taken. These are shown in Figs. 26 and 27. In Fig.26, The K2 $\mathrm{p}_{3 / 2}$ and $2 \mathrm{p}_{1 / 2}$ peaks are clearly observed, and C1s peak showed the presenc of C-F bonding. The F1s peak in Fig. 27 showed the presence of a C-F peak plus a lower peak attributed to a metal fluoride. This confirms the presence of a fluoroploymer which as reported may be due to contamination. The metal fluoride peak cannot be explained, however the presence of fluorides as constituents of lunar magmatic gases cannot be ruled out (Goldberg, 1976). The Fe peak in Fig. 27 is present as an oxide.

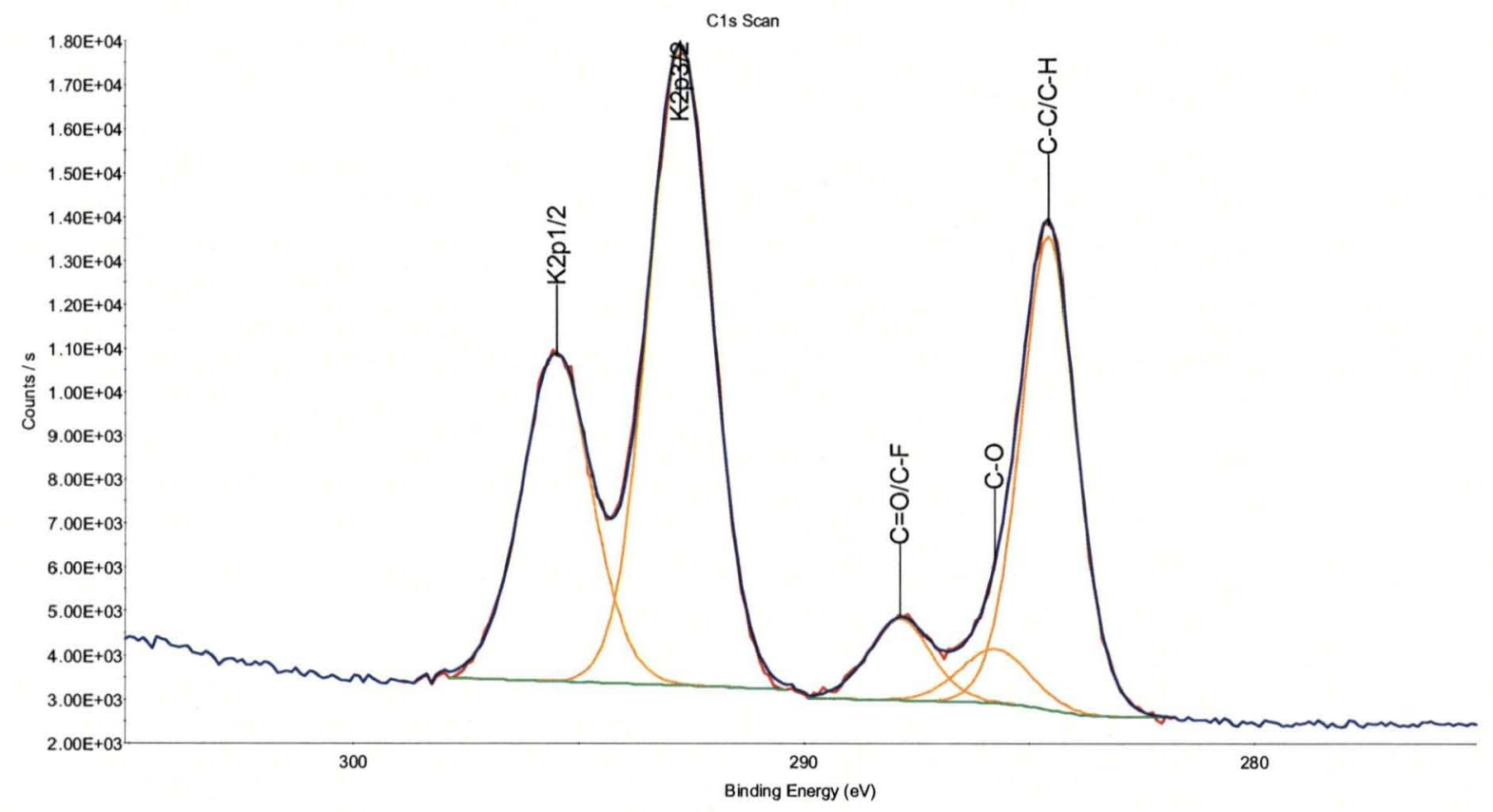

Figure 26: Narrow scans of the $\mathrm{K}$ and $\mathrm{C}$ peaks on sample \#2051. 


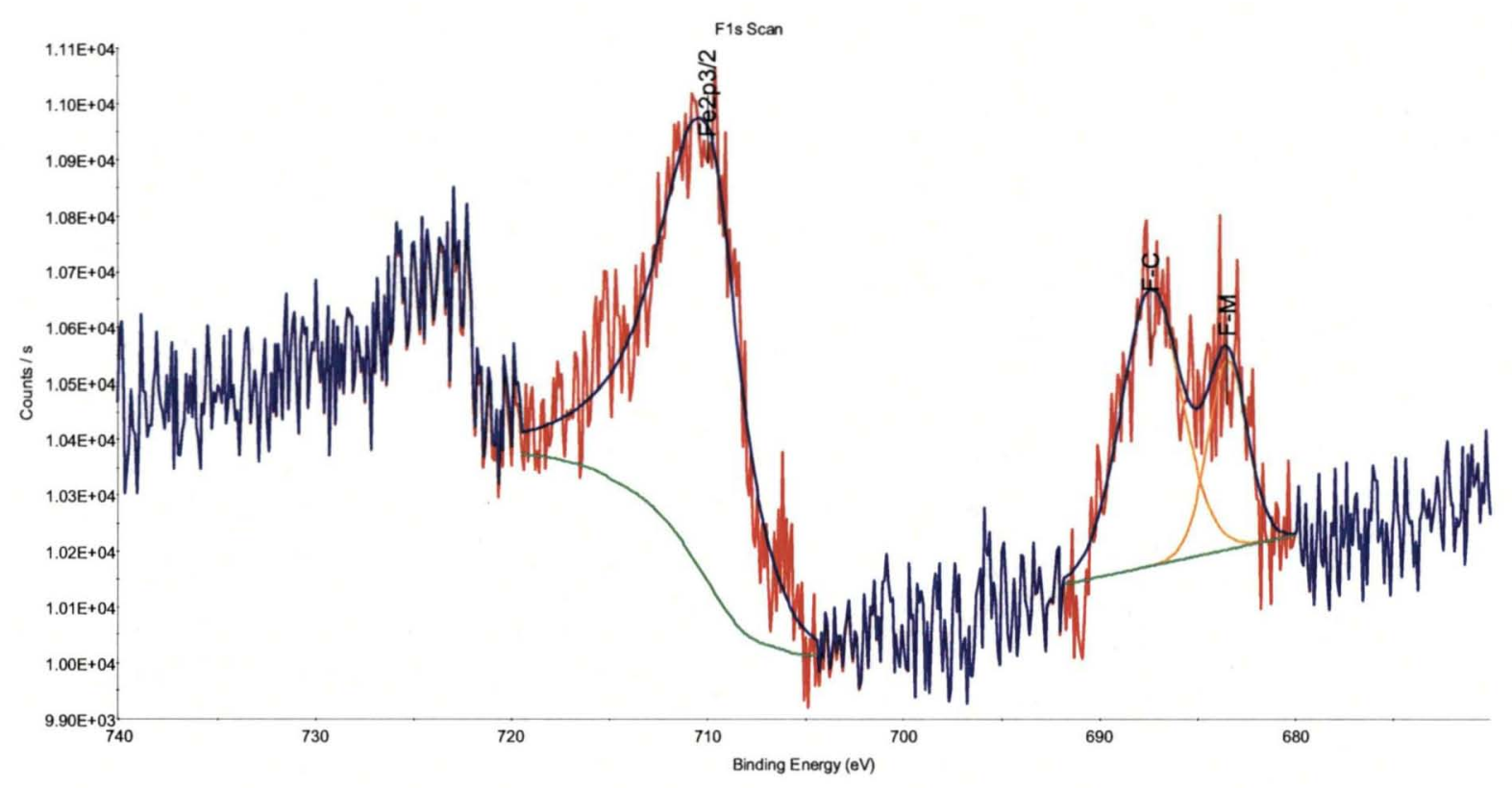

Figure 27: Narrow scans of the Fe and F peaks on sample \#2051.

\section{CONCLUSIONS}

Computational work to determine the influence of the Apollo 12 flyby on Surveyor III is discussed. Saltation velocity threshold formulas (Sagan, 1990) have been implemented in Mathematica and FORTRAN and compared to the gas saltation velocity computed from the Fluent CFD (Dr. Xiaoyi Li - GRC). Sagan (1990) predicts interparticle cohesion forces on the order of nano Newtons for particles in the range of 10 to $100 \mu \mathrm{m}$ while Walton (2008) predicts a cohesion force about 1000 times larger. Even for the small Sagan cohesion force, particles are not predicted to make it to the Surveyor III site at $R=109 \mathrm{~m}$. The results of these simulations are summarized as follows:

(1) Particles less than $13 \mu \mathrm{m}$ diameter $D$ can be ejected the full distance from the LM ground track to the Surveyor III site (a minimum distance of $109 \mathrm{~m}$ ).

(2) Particles in the size range of $17 \mu \mathrm{m}<D<2600 \mu \mathrm{m}$ can be lifted by the gas shear stress, based on the $h=45 \mathrm{~m}$ case from Xiaoyi.

(3) Even in the $h=45 \mathrm{~m}$ case, (1) and (2) above do not overlap, so that no particles will be ejected the full $109 \mathrm{~m}$ to the Surveyor site.

The actual nozzle height is $67 \mathrm{~m}$, but we only have the simulations for $h=25$ and $45 \mathrm{~m}$. Based on a rough extrapolation estimate, no particles will be lifted for the $h=67 \mathrm{~m}$ case. However, it is believed that secondary collisions of larger particles with the surface soil may likely lead to smaller particles being ejected and impacting the Surveyor, possible coating it with a layer of fine dust.

Computational work also done to model of the soil pressurization during a lunar landing and the outgasing from the soil after the engines are shut down. The time taken to significantly off-gas 
the soil was predicted for various conditions and range of parameter values. This was compared to the observed dust settling time ( $\sim 30$ seconds) obtained from the Apollo landing videos. These simulations show that the time constant associated with the outgasing is consistent with the optical opacity decay seen in the Apollo videos.

X-ray Photoelectron Spectroscopy (XPS) measurements of Surveyor III samples have been performed on coupons which either faced towards or away from the Apollo 12 LM. A 30 micron $\mathrm{X}$-ray spot size was used to analyze embedded particles for compositional differences. The XPS data were compared to Apollo 12 data from the Lunar and Planetary Institute. X-ray Photoelectron Spectroscopy (XPS) measurements of Surveyor III samples were performed. Multiple spots along darkened and lighter regions of the samples have been measured, and the chemical compositions were correlated. The XPS data taken on samples from the Surveyor III camera housing show the presence of lunar regolith. The concentration of elements comprising the lunar regolith were determined to be in higher concentrations in the darker areas of the samples \#2048 and \#2050.

\section{ACKNOWLEDGEMENTS}

The authors would like to thank Dr. Stephen Perusich for providing the historical background and organizing the original project report, "Surveyor III / Apollo 12 Particle and Charge Dynamics”, ASRC Final Task Order Report, December 31, 2010.

\section{REFERENCES}

Aronowitz, L., "Electrostatic Potential Generated by Rockets on Vehicles in Space," IEEE Trans. Electromagnetic Compatibility, EMC-10, 341 (1968).

Carroll, W. F., P. M. Blair, "Discoloration and Lunar Dust Contamination of Surveyor III Surfaces," Proc. Second Lunar Sci. Conf., 3, 2735 (1971).

Colwell, J. E. , S. R. Robertson, M. Horányi, X. Wang, A. Poppe, and P. Wheeler, "Lunar Dust Levitation," J. Aerospace Eng., January, 2 (2009).

Eskin, D., S. Voropayev, "An Engineering Model of Particulate Friction in Accelerating Nozzles," Powder Tech., 145, 203 (2004).

Goldberg, R.H., R.A. Weller, T.A. Tombrello, \& D.S. Burnett, "Surface concentrations of F, H, and C", Lunar and Planetary Science Conf., Vol. 7, p.307, 1976

Heiken, G.H., D.T. Vaniman, B.M. French_Lunar Sourcebook; A user's guide to the moon, Eds., Lunar and Planetary Institute, 1991.

Immer, C., P. Metzger, P. Hintze. A. Nick, \& R. Horan, "Apollo 12 lunar module exhaust plume impingement on lunar Surveyor III", doi:10.1016/j.icarus.2010.11.013

Iversen, J.D, B.R. White, "Saltation Threshold on Earth, Mars, and Venus", Sedimentology, 29, 1982, pp. 111-119.

Kalman, H., A. Satran, D. Meir, and E. Rabinovich, "Pickup (Critical) Velocity of Particles," Powder Tech., 160, 103 (2005).

Mazumder, M. K., P. K. Srirama, R. Sharma, A. S. Biris, I. Hidetaka, S. Trigwell, and M. N. Horenstein, "Lunar and Martian Dust Dynamics," IEEE Ind. Appl. Magazine, July/Aug, 14 (2010).

Rabinovich, E., H. Kalman, "Pickup, Critical, and Wind Threshold Velocities of Particles," Powder Tech., 176, 9 (2007).

Sagan, C., Christopher Chyba, “Triton’s Streaks as Windblown Dust,” Nature, 346, 1990, pp. 546-548. 
Simoneit, B. R., A. L. Burlingame, "Organic Analyses of Selected Areas of Surveyor III recovered on the Apollo 12 Mission,” Nature, 234, 210 (1971).

Trigwell, S., D. Boucher, and C. I. Calle, "Electrostatic Properties of PE and PTFE Subjected to Atmospheric Pressure Plasma Treatment; Correlation of Experimental Results with Atomistic Modeling," J. Electrostatics, 65, 401 (2007).

Walton, O.R., "Review of Adhesion Fundamentals for Micron-Scale Particles", Powder and Particle Journal, 26, 2008, pp. 129-141. 